Hunnewell, R. W., A. W. Diamond, and S. C. Brown. 2016. Estimating the migratory stopover abundance of phalaropes in the outer Bay of Fundy, Canada. Avian Conservation and Ecology 11(2):11. http://dx.doi.org/10.5751/ACE-00926-110211

Copyright (C) 2016 by the author(s). Published here under license by the Resilience Alliance.

Research Paper

\title{
Estimating the migratory stopover abundance of phalaropes in the outer Bay of Fundy, Canada
}

Robin W. Hunnewell ${ }^{1,2}$, Antony W. Diamond ${ }^{3}$ and Stephen C. Brown ${ }^{4}$

${ }^{1}$ Environment Canada, ${ }^{2}$ University of New Brunswick, ${ }^{3}$ Atlantic Lab for Avian Research, University of New Brunswick, ${ }^{4}$ Manomet Inc.

ABSTRACT. We investigated the abundance and turnover rate of phalaropes (Red-necked and Red: Phalaropus lobatus, Phalaropus fulicarius) in the outer Bay of Fundy, Canada during migratory stopover in 2008, 2009, and 2010. We describe estimation procedures designed to calculate size of the total stopover population of phalaropes, adjusting for length of stay. A total of 29 aerial surveys were flown in two nonoverlapping survey regions situated off Brier Island, Nova Scotia and Grand Manan, New Brunswick. Line transect distance sampling methods were used to obtain abundance estimates at discrete time steps from aerial surveys. Estimated number of phalaropes by date ranged between $6000-88,000$ in 2009 and 31,000-127,000 in 2010. To quantify the cumulative number of phalaropes in the study area, the temporal dimension of stopover passage was incorporated by an analysis of radiotelemetry data to estimate length of stay. A total of 27 phalaropes were captured and fitted with radio transmitters between 2008 and 2010 . Estimated length of stay in days was $15.2 \pm 1.91$ for a time-integrated stopover population of 103,496 phalaropes in 2009 and 287,558 in 2010 . This is particularly relevant to the conservation status of P. lobatus in North America, which has been uncertain since the disappearance of that species from an important stopover site in 1990. Our findings emphasize the need for studies that monitor phalaropes at sea, where they spend the majority of their time, as a means to inform effective management and conservation.

\section{Estimation de l'abondance de phalaropes à des haltes migratoires dans la partie extérieure de la baie de Fundy, Canada}

RÉSUMÉ. Nous avons examiné l'abondance et le taux de passage des phalaropes (à bec étroit et à bec large : Phalaropus lobatus, Phalaropus fulicarius) dans la partie extérieure de la baie de Fundy, Canada, durant les haltes migratoires de 2008, 2009 et 2010. Nous décrivons la méthodologie employée pour le calcul de la taille de la population de phalaropes de passage, y compris l'ajustement nécessaire pour tenir compte de la durée du séjour des oiseaux. Vingt-neuf relevés aériens ont été effectués au-dessus de deux régions ne se chevauchant pas, l'une au large de l'île Brier en Nouvelle-Écosse, l'autre au large de l'île Grand Manan au Nouveau-Brunswick. Pour obtenir des estimations ponctuelles de l'abondance, un échantillonnage par la méthode des transects et tenant compte de la distance des observations a été choisi. Ces estimations ponctuelles des effectifs de phalaropes variaient de 6000 à 88000 en 2009 et de 31000 à 127000 en 2010. Pour quantifier le nombre cumulatif de phalaropes dans l'aire d'étude, la dimension temporelle du passage aux haltes a été incorporée en estimant la durée de séjour à l'aide de l'analyse de données radio-télémétriques. Vingt-sept phalaropes ont été capturés et munis d'un émetteur radio de 2008 à 2010. La durée du séjour a été évaluée à 15,2 $\pm 1,91$ jours, ce qui permet l'estimation de la population de passage (qui intègre la durée de séjour) à 103496 phalaropes en 2009 et à 287558 en 2010 . Ces estimations sont tout particulièrement utiles pour déterminer le statut de conservation de P. lobatus en Amérique du Nord, lequel est incertain depuis la disparition de l'espèce d'une importante halte migratoire en 1990. Nos résultats mettent en lumière le besoin de suivis des phalaropes en mer, où ils passent le plus clair de leur temps, afin d'orienter les mesures de gestion et de conservation pour qu'elles soient les plus efficaces possibles.

Key Words: abundance estimates; aerial line transects; Bay of Fundy; distance sampling; phalarope

\section{INTRODUCTION}

Phalaropes are unique among shorebirds in that they are built for surface swimming with specialized traits including lobed toes and dense belly plumage for an impressive buoyancy (Warnock et al. 2002). Red-necked Phalaropus lobatus and Red Phalaropes $P$. fulicarius have Holarctic breeding ranges and spend up to nine months of the year at sea (Rubega et al. 2000, Tracy et al. 2002). Our work focuses on these two pelagic species, hereafter "phalaropes."
In marine environments, phalaropes rely upon oceanographic processes that serve to lift their zooplankton prey to the surface. For example, they have been observed feeding at continental shelf breaks (Haney 1985), major oceanic currents (Murphy 1936), coastal upwelling zones (Briggs et al. 1984, DiGiacomo et al. 2002), edges of pack ice (Orr et al. 1982), and mud plumes created by the benthic feeding of grey whales (Obst and Hunt 1990). Many studies have examined the dynamics of such processes because they play a key role in the formation and persistence of prey patches, concentrating buoyant organisms at the surface 
(Wolanski and Hamner 1988, Franks 1992, Genin 2004) and providing a critical point of contact between marine birds and their prey (Hunt et al. 1998, Yen et al. 2004, Bost et al. 2009).

The Bay of Fundy is a biologically rich marine area that is dominated by strong tidal forcing and provides stopover habitat for phalaropes on migration. During postbreeding migration, mixed flocks feed in tidal eddies generated by fast moving currents over ledges (Brown and Gaskin 1988). Our goal was to conduct targeted surveys for phalaropes in the outer Bay of Fundy, where migrants of $P$. lobatus occur in spatial and temporal overlap with migrants of $P$. fulicarius. Abundance estimates are important because, on account of their pelagic ecology, phalaropes have eluded the major, omnibus shorebird monitoring programs in North America, such as the International Shorebird Survey (ISS) and the Atlantic Canada Shorebird Survey (ACSS), formerly known as the Maritimes Shorebird Survey (MSS). These migration monitoring efforts were originally designed to identify important shorebird staging habitats, but because phalaropes use offshore marine areas, they fall outside the ambit of most periodic survey routines (Brown et al. 2010).

The need for phalarope surveys during the pelagic phase of their ecology was amplified by a conspicuous decline of Red-necked Phalaropes from a reliable stopover site in the 1980s. During postbreeding migration, full migratory passage of the species at this site was estimated at 1-2 million birds (Finch et al. 1978, Vickery 1978, Mercier and Gaskin 1985). Composed wholly of $P$. lobatus and concentrated within a foraging area of approximately $100 \mathrm{~km}^{2}$ known as Head Harbour Passage in the western Bay of Fundy, vast flocks staging in the area each year began to decline in the mid-1980s and by 1990 had disappeared altogether (Duncan 1996). Because they have not returned, the crash triggered broad concern for the conservation status of the species (Donaldson et al. 2000, Brown et al. 2001), prompting recommendations to assess remaining numbers of $P$. lobatus in the northeastern U.S. and Canadian Maritimes (Brown et al. 2010). In 2014, the Committee on the Status of Endangered Wildlife in Canada (COSEWIC) designated the species as one of Special Concern (http://www.registrelep-sararegistry.gc.ca/species/ speciesDetails_e.cfm?sid=1278).

We report the results of estimation procedures designed to calculate the size of the total stopover population of phalaropes in the outer Bay of Fundy, while adjusting for incomplete detection and estimated length of stay. We discuss constraints of aerial surveys for ephemeral, mixed flocks of phalaropes at sea, as well as conservation implications of our present-day findings with respect to the disappearance of $P$. lobatus from the western Bay of Fundy some 25 years ago.

\section{METHODS}

\section{Study area}

Aerial surveys to estimate stopover abundance and turnover of phalaropes were conducted during postbreeding migration in 2009 and 2010 in the outer Bay of Fundy, Canada. The study area comprised two nonoverlapping survey regions located off Brier Island, Nova Scotia and Grand Manan, New Brunswick (Fig. 1). Characterized by strong tidal forcing and irregular bottom topography, both regions contain ledges and shoals that introduce turbulence into the prevailing axis of tidal flow (Aretxabaleta et al. 2008). As it collides with ledges (e.g., Northwest Rock $44^{\circ} 19^{\prime} \mathrm{N}$, $66^{\circ} 24^{\prime} \mathrm{W}$ ), eddies of cool, upwelled water carrying dense prey form, drift, and degrade locally about the ledges $(\leq 1100 \mathrm{~m})$, subject to the agency of semidiurnal ebb-flood cycle (Thorne and Read 2013). Phalaropes exhibit positive spatial association with these patches of vertical mixing in the surrounding marine environment (Brown and Gaskin 1988).

Fig. 1. Location of study area in the outer Bay of Fundy, Canada between New Brunswick and the southwestern tip of Nova Scotia. Marine depth contours, range -5 to $-100 \mathrm{~m}$, are shown. Aerial line transects $(n=28)$ were allocated over two nonoverlapping survey regions, "Brier" and "Grand Manan." Strong tidal currents collide with ledges and shoals to generate enhanced vertical mixing in both regions. Note: location of Head Harbour Passage where large flocks of P. lobatus staged until the mid-1980s shown in upper left corner.

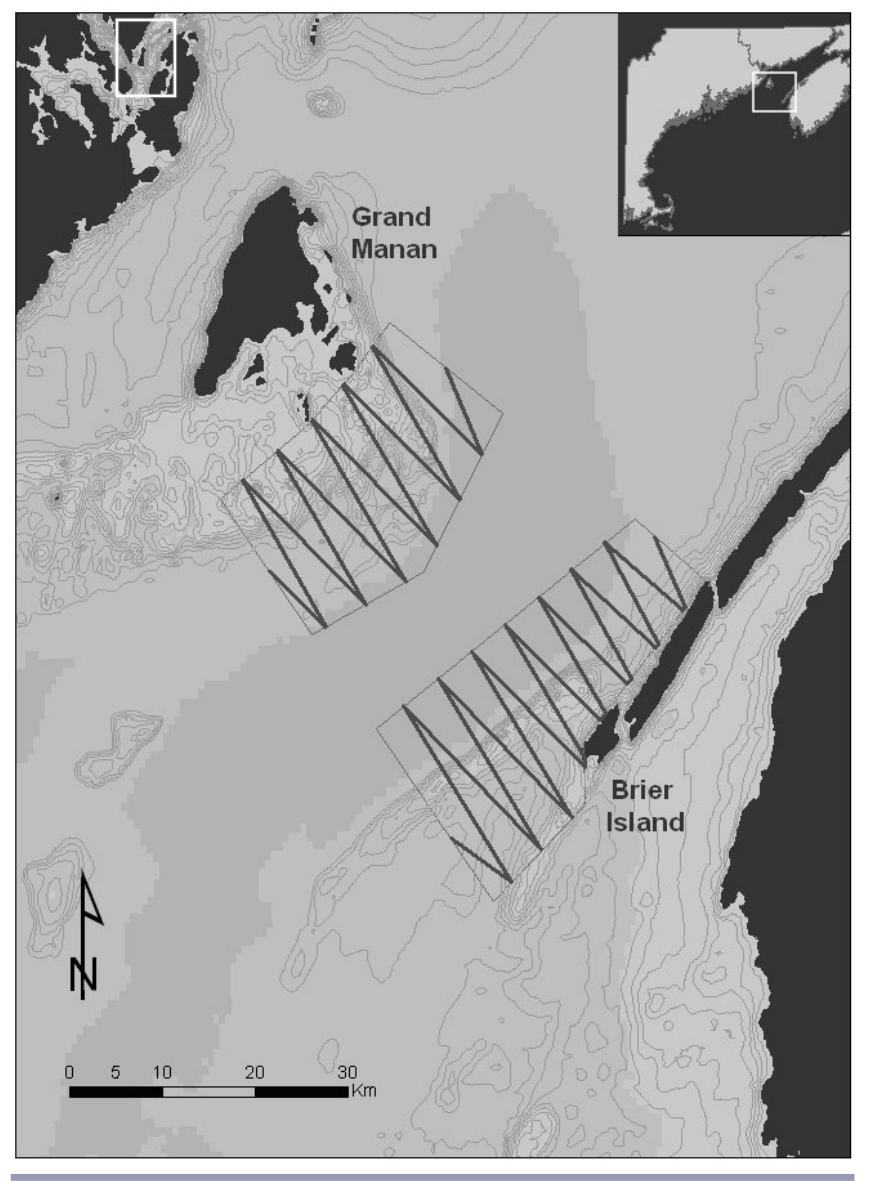

Aerial surveys were flown in survey regions, herein "Brier" and "Grand Manan," situated on either side of a shipping channel. Steep ledges in both regions host large, mixed flocks of phalaropes, relative to other parts of the surrounding Gulf of Maine (Brown et al. 2010). Both survey regions were demarcated to be of comparable size ( $633 \mathrm{~km}^{2}$ and $531 \mathrm{~km}^{2}$, respectively) and configuration with respect to surrounding depth gradients that change abruptly from $<10 \mathrm{~m}$ over the ledges to $>220 \mathrm{~m}$ in the shipping channel. 


\section{Aerial survey design and protocol}

To ensure uniform coverage probability within each region, a line transect layout was established in advance of surveys. Following recommendations by Thomas et al. 2007, a systematic design for transect placement was implemented with the total length of transects $(458 \mathrm{~km})$ allocated over 28 lines averaging $16 \mathrm{~km}$ in length. Exploratory flights had indicated that on average higher densities of phalaropes would be encountered in the Brier region; therefore a larger number of transects was assigned to Brier ( $\mathrm{n}=$ 16) than Grand Manan $(n=12)$. To minimize airtime spent in transit between replicate lines, a zig-zag geometry with equal 4$\mathrm{km}$ spacing was selected (Fig. 1). Transects were oriented perpendicular to the prevailing axis of tidal flow and corresponding trend in the spatial distribution of phalaropes. The cross-current orientation was used to prevent spurious imbalances in the set of line-to-object distances obtained from surveys and to give lower variance for the encounter rate across replicate lines (Thomas et al. 2007, Fewster et al. 2009).

Although opportunities depended on weather and fog, we conducted all surveys independently of tidal stage on days with optimal conditions of zero fog and sea state (Beaufort scale) of $0-3$. Time needed to complete a full survey was no more than 3 hours; mean duration (h) was 2.67 ( $\max 3.03)$. Surveys were flown throughout the migration of postbreeding phalaropes in the study area, a period that typically spans $8-10$ weeks beginning in midJuly and tapering off by mid- to late September (Orr et al. 1982, Rubega et al. 2000, Tracy et al. 2002).

The survey platform was a twin-engine aircraft with low wings and flat-sided windows flying at a speed of 100 knots. Surveys were flown at varying altitude; range $80-182 \mathrm{~m}$, mean ( \pm st dev) $126.9 \pm 21.5$ in 2009 and range $94-169 \mathrm{~m}$, mean $128.7 \pm 11.2$ in 2010. Phalarope flocks were visually identified from the air by an observer stationed in aft seats, scanning to one side of the aircraft. A global positioning system (GPS) including two Garmin units (GPSMap 76, eTrex Vista Cx) was used to log position, altitude, and speed at 5-s intervals and to store a specific waypoint whenever a flock sighting occurred.

Sighting data included flock size and downward viewing angle to the detected flock. To facilitate taking angle measurements, a set of bins demarcating the search strip were used to collect sightings from the air. We used two plexiglass angle boards to define the bins based on vertical angle measurements: $30^{\circ}-35^{\circ}-40^{\circ}-50^{\circ}-60^{\circ}-70^{\circ}-80^{\circ}$ (Bengston et al. 1996). Fitted in both windows, the boards denoted the bins with marks calibrated to observer height. A second set of strips on the trailing edge of the aircraft wing was used as a peripheral aid to maintain standard head alignment. Viewed through the angle boards, each flock was assigned a sighting bin number as it passed abeam within the field of view.

The observer scanned continually to one side of transects, alternating between left and right seats as needed to maintain a glare free prospect of the search strip. Downward visibility was limited by the flat-sided windows. Width of the search strip was determined by an available field of view, which was bounded below at $30^{\circ}$ and above at $80^{\circ}$. Sitting upright, the observer could not search within a viewing angle of $30^{\circ}$ from the vertical. Thus at any altitude, a near-line blind strip beneath the plane obscured flocks from view. Other than bounding it at $80^{\circ}$ for flocks near horizon, no attempt was made to delimit the search strip.
Because time to process flock sightings from the air was limited, we confined bin classification to the geometric centroid of flock clusters, as recommended in Buckland et al. 2001. Because species composition of flocks could not be discerned from the air, sightings were recorded as "phalaropes" and examined together (cf. Herr et al. 2009). Whenever a flock sighting occurred, the observer announced flock size and sighting bin number through headset microphone to a digital voice recorder. Spoken-entry data were uploaded to a WAV file, which generated a time code to reference each sighting in a survey.

Perpendicular distances $(x)$ were calculated from measurements of angle $(a)$ and altitude $(H)$ at the time a sighting was made, using basic trigonometry $x=H \cdot \tan (a)$. We employed a procedure of discretizing viewing angles, obtained in situ as grouped data using bins, by rounding to the nearest midpoint articulating each bin (e.g., flocks assigned to bin 3 were rounded to $45^{\circ}$ ). This allowed us to achieve an ungrouped perpendicular distance, calculated from a rounded angle and stored altitude at the time a sighting was made, for each flock. All flock positions, eastings and northings relative to the flown line, were georeferenced in ArcGIS 10 (ESRI).

To evaluate the species composition of mixed flocks on the water, we conducted boat-based surveys in 2010. All boat-based surveys were carried out opportunistically on calm days with flat seas (Beaufort $0-1)$ and confined to accessible areas $\left(\leq 10 \mathrm{~km}^{2}\right)$ around the Brier Island ledges.

\section{Model fitting and analysis}

A detection function for phalaropes was estimated from the perpendicular distances of detected flocks to the flown line by means of conventional distance sampling methods, described in Buckland et al. 2001 and 2004. Because it is expected that a proportion of objects will be missed, analysis procedures specify a flexible, semiparametric model for the detection function $g(x)$ and use model fit to infer this proportion (Thomas et al. 2010). Standard estimators describe change in detection relative to an assumed intercept; detection is assumed to be certain on the line itself at zero distance, $g(0)=1$.

For the distance detections gathered here, visibility on the line itself was not possible. Because of the flat-sided windows, a nearline blind strip existed such that distances $0-46 \mathrm{~m}$ were hidden from view while distances $47-105 \mathrm{~m}$ were intermittently available, depending on survey altitude. When detection probability is subject to the anatomy of a blind strip, left-truncation may ensure a plausible shape for detection curves (Alldredge and Gates 1985, Quang and Lanctot 1991). We considered left truncating at $x=$ $100 \mathrm{~m}$ to retain the assumption $g(0)=1$, but 477 flock sightings would have been discarded by this move. Therefore, we employed an offset method of rescaling distance data to the minimum observable distance $\left(x_{\text {min }}\right)$ from the flown line, computed from the minimum viewing angle $\left(a_{\text {min }}=30\right)$ and altitude $(H)$ at the time of each sighting. In this way, detection functions were offset and detection was assumed to be certain, or nearly so, at the nearest visible distance from the line, $g\left(x_{\min }\right)=1$. To implement this, all perpendicular distances were rescaled accordingly: $x_{\text {offset }}=x-x_{\text {min }}$ (Laake et al. 2008b).

We analyzed the data separately by survey region and by year (Brier 2009, 2010, Grand Manan 2009, 2010), enabling a 
comparison of detection parameters estimated at levels relevant to this study. The decision to conduct separate analyses by year was unambiguous because it was not meaningful to obtain pooled estimates of abundance across years. Desired gains in precision by fitting a separate detection function by region, however, were formally evaluated. Resulting Akaike weights were checked throughout the model fitting routine to confirm whether this improved model fit (Buckland et al. 2001). We estimated detection probability "globally" (region:yr), using poststratification to obtain abundance estimates by survey date. This level of temporal resolution in the data was of intrinsic interest in calculating the size of the stopover population.

All detection probability analysis was performed in program DISTANCE, version 6.1 Beta 1 (Thomas et al. 2010). Model fitting was based on a set of key functions and series adjustment terms to improve fit. Data grouping was enlisted at the analysis stage to address any evidence of heaping in the data relative to estimated detection curves. We explored data groupings and right truncation widths as a means to diagnose model fit and capture disparity between observed probability of detection and the fitted curve of estimated detection models. Where appropriate, Akaike's Information Criterion (AIC) was used for model selection, while chi-squared goodness-of-fit was used to evaluate function forms with respect to data groupings. To generate estimates of density $(D)$ and abundance $(N)$ of phalaropes by survey date under each of the four (region:yr) detection functions used, expected flock size $E(s)$ was needed along with estimated density of flocks. Accordingly, flock size was estimated globally (region:yr) using the size biased-regression method in which $\ln$ (cluster size) is regressed against estimated $g(x)$.

\section{Estimating length of stay}

To adjust for turnover or length of stay, we derived a correction factor based on an analysis of radio-marked birds in the study area. In 2008, 2009, and 2010, a total of 27 phalaropes were fitted with VHF radio transmitters (1.2 grams, 6 wk lifespan, Holohil Systems, Ltd.). Full description of materials and methods designed to capture phalaropes at sea is given in Ronconi et al. 2010. Tags were deployed in mid- to late August of each year. From the first date of deployment, aerial telemetry to monitor the site tenure of radio-marked birds was conducted every other day at high altitude, $650 \mathrm{~m}$, for a signal range of $8-10 \mathrm{~km}$. Time needed to relocate tagged birds in the study area was $\leq 15 \mathrm{~min}$. After $1 \mathrm{hr}$, telemetry ceased until the following attempt. If a signal could not be relocated after three consecutive attempts, the bird was considered to have migrated on the day of its last detection.

Measured as the elapsed number of days between capture and final detection at a site, minimum length of stay may be estimated from the observation times of radio-marked birds (Iverson et al. 1996), but this neglects precapture site tenure on the part of birds. Therefore, we used encounter sampling (Otis et al. 1993) and program DISTANCE (Thomas et al. 2010) to estimate length of stay (Farmer and Durbian 2006). We assumed that (1) the probability of a bird being caught was proportional to its length of stay, (2) a bird had an equal probability of being caught at any juncture of its stay, and (3) marked birds were representative of unmarked birds (Lehnen and Krementz 2005). Under these assumptions, we fitted a probability density function to the observation times and used the DISTANCE parameter "effective strip width," $\mu$, i.e., that distance for which as many objects are detected beyond $\mu$ as are missed within $\mu$ for a given model (Buckland et al. 2001), as an estimate for length of stay in days. As the effective proportion of recorded observation times, this gave an estimate that factored in the likelihood of birds being captured upon arrival and successfully relocated until departure from the study area.

\section{Calculating size of stopover population}

As snapshots of phalarope abundance at discrete time steps, each aerial survey was used to track fluctuations in stopover population size across the survey period. In both years, the survey period from initial to final survey date was divided into subintervals, days, to find a cumulative number of phalaropes for all values of date and abundance, "bird days." Hence if $b_{1}$ is the estimated abundance on survey date $t_{1}$, as determined from the detection model, bird days was found by numerical integration of coordinate pairs $\left(t_{1}, \mathrm{~b}_{1}, \mathrm{t}_{2}, \mathrm{~b}_{2} \ldots \mathrm{t}_{\mathrm{f}}, \mathrm{b}_{\mathrm{f}}\right)$. Stopover population was estimated by $p o p=b d / L O S$, where $p o p=$ stopover population, $b d$ $=$ bird days and $L O S=$ estimated length of stay in days (Farmer and Durbian 2006).

Variance of total stopover population size estimates arose from multiple components: survey date abundance estimates $\left(b_{t}\right)$ generated by the detection models, and estimated length of stay, also derived from a detection function model. We report associated coefficients of variation and $95 \%$ confidence limits for the abundance estimates and estimated length of stay.

\section{RESULTS}

Aerial line transect surveys were conducted from 31 July to 14 September in 2009 and 26 July to 12 October in 2010. In all, we flew 29 surveys (15 in 2009; 14 in 2010) for a total of 12,667 km and 2159 flock sightings recorded. Time intervals between surveys ranged from 1-8 days, mean ( \pm st dev) $3.7 \pm 2.6$ in 2009 and $2-$ 11 days, mean $6.4 \pm 2.8$ in 2010 . Fog in the study area prevented the first survey until the end of July in both years. On three occasions, survey effort was curtailed by fog that formed near Grand Manan and we flew transects in Brier only. On three occasions we flew back-to-back surveys in the course of a single day to assess changes in phalarope habitat specificity with respect to tidal stage. In 2010, the time frame for surveys (78 days) was protracted relative to that in 2009 (45 days) as flocks remained in the study area until mid-October. In response, we continued to fly surveys until October 12 .

A combination of global detection models was fitted to the data partitioned by year $(2009 ; 2010)$. Candidate models with lowest AIC were based on a half-normal key with simple polynomial or cosine adjustment terms. Nested within respective years, we compared models fitted to the data pooled across regions (Brier, Grand Manan) with estimating detection probability separately by region. Summed AIC values from models fitted to the regionspecific data (2571 in 2009, 4104 in 2010) were consistently less than AIC values from models fitted to the region-pooled data ( 2591 in 2009, 4118 in 2010). Therefore on the basis of improved model fit, we focused our analysis on models fitted to the data separately by region:yr. 
Table 1. Parameter estimates ( $p, E S W$ ) for detectability of phalarope flocks from detection functions fitted with various data groupings. Global detection functions were fitted to data pooled across survey dates at four levels (region:yr). All models used a half-normal key with simple polynomial or cosine adjustment terms. For each model, $p$ refers to the estimated average detection probability and $E S W$ refers to the effective strip width. Standard error (SE) and \%CV are reported for $p$. The chosen data grouping for each of the four models was ranked by highest Chi-p values and on basis of fit at the left-edge of the detection curve.

\begin{tabular}{|c|c|c|c|c|c|c|c|}
\hline Region: Year & Data grouping & Right-truncation (m) & $p$ & $\mathrm{SE}$ & $\% \mathrm{CV}$ & $E S W$ & GoF Chi-p \\
\hline Brier 2009 & six unequal bins & 340 & 0.372 & 0.013 & 3.60 & 126.50 & 0.001 \\
\hline Brier 2009 & ten $34-\mathrm{m}$ bins & 340 & 0.378 & 0.018 & 4.80 & 128.37 & 0.070 \\
\hline Brier 2009 & fifteen $23-\mathrm{m}$ bins & 350 & 0.368 & 0.018 & 4.99 & 128.82 & 0.890 \\
\hline Brier 2009 & eight 40-m bins & 320 & 0.397 & 0.020 & 5.14 & 126.97 & 0.522 \\
\hline Grand Manan 2009 & six unequal bins & 340 & 0.299 & 0.014 & 4.61 & 101.80 & 0.000 \\
\hline Grand Manan 2009 & ten $34-\mathrm{m}$ bins & 340 & 0.298 & 0.020 & 6.65 & 101.15 & 0.000 \\
\hline Grand Manan 2009 & eight $40-\mathrm{m}$ bins & 320 & 0.322 & 0.014 & 4.36 & 102.95 & 0.072 \\
\hline Grand Manan 2009 & ten $30-\mathrm{m}$ bins & 300 & 0.326 & 0.024 & 7.27 & 97.68 & 0.098 \\
\hline Brier 2010 & six unequal bins & 340 & 0.331 & 0.015 & 4.54 & 112.63 & 0.036 \\
\hline Brier 2010 & ten $34-\mathrm{m}$ bins & 340 & 0.317 & 0.013 & 4.08 & 107.82 & 0.000 \\
\hline Brier 2010 & seven $40-\mathrm{m}$ bins & 280 & 0.410 & 0.016 & 3.95 & 114.79 & 0.010 \\
\hline Brier 2010 & six mixed bins ${ }^{\dagger}$ & 360 & 0.318 & 0.010 & 3.12 & 114.38 & 0.258 \\
\hline Grand Manan 2010 & six unequal bins & 340 & 0.281 & 0.013 & 4.50 & 95.67 & 0.000 \\
\hline Grand Manan 2010 & ten 34-m bins & 340 & 0.261 & 0.011 & 4.18 & 88.83 & 0.005 \\
\hline Grand Manan 2010 & seven $40-\mathrm{m}$ bins & 280 & 0.346 & 0.015 & 4.35 & 96.80 & 0.048 \\
\hline Grand Manan 2010 & six mixed bins ${ }^{\dagger}$ & 360 & 0.261 & 0.008 & 2.90 & 94.06 & 0.429 \\
\hline
\end{tabular}

${ }^{\dagger} 6$ mixed distance bins: $34-\mathrm{m}$ bin followed by a $46-\mathrm{m}$ bin and four equal $70-\mathrm{m}$ bins.

Empirical line-to-object distances obtained from surveys exhibited a nonuniform pattern of detection relative to the leftedge of fitted curves, characterized by a "shortage" of sightings in the first bin, followed by a spike or "surplus" in the second. We anticipated a lack of fit between observed detection and estimated detection curves owing to the presence of a blind strip and varying survey altitude. Thus we used the offset method and rescaled distance data to accommodate the blind strip. However, visual inspection of offset detection curves revealed a remaining lack of fit. Rounding to favored values can cause heaping in distance data (Buckland et al. 2001) and we judged that the aerial sighting process led to visibility bias affecting the first and second sighting bins, which induced a systematic lack of fit. Various data groupings were enlisted to alleviate heaping and achieve a robust fit for each model. After regrouping the data into distance classes that spread line-to-object distances across the spiked pattern, we selected a data grouping that achieved best fit overall.

To evaluate the various groupings used with each model, we did not rely upon selection criteria such as AIC, which is not valid to select among data groupings used with the same model (Buckland et al. 2001). Care was taken not to evaluate model fit solely on the basis of chi-squared tests either, which can be sensitive to the choice of distance classes underlying the test (Fewster et al. 2008). Thus for the Brier 2009 model, the data grouping that yielded best fit as assessed by chi-squared test consisted of 15 bins out to a right-truncation of $350 \mathrm{~m}$ ( $p$-value $=0.890)$. Nevertheless, a set of 8 bins out to $320 \mathrm{~m}$ ( $p$-value $=0.522$ ) was selected as the most optimal data grouping, especially in the critical realm of fit at the left-edge of the detection curve (Fig. 2). Once detection functions were offset to accommodate the blind strip, $98 \%$ of flock sightings occurred at $\leq 340 \mathrm{~m}$.

Parameter estimates for probability of detection $p$ and effective strip width $E S W$ remained stable over the various data groupings used with each (region:year) model, indicating a good overall fit (Table 1). Probability of detection estimated by each of the four chosen models was: 0.39, 0.31 in Brier 2009, 2010 and 0.32, 0.26 in Grand Manan 2009, 2010. Corresponding point estimates for density $(D)$ and abundance $(N)$ of phalaropes by survey date are given in Table 2.

Fig. 2. Comparison of data groupings enlisted to achieve robust model fit for the same detection function. Brier 2009 analysis set shown, i.e., distance data obtained from surveys flown in Brier, 2009. Figures show observed probability of detection in each distance class (histograms) against expected probability of detection (blue lines) estimated by the fitted model. Eight $40 \mathrm{~m}-$ distance bins out to $320 \mathrm{~m}$ achieved most optimal fit on basis of $x^{2} \mathrm{p}$-value as well as visual inspection of fit at the left-edge of the detection curve.
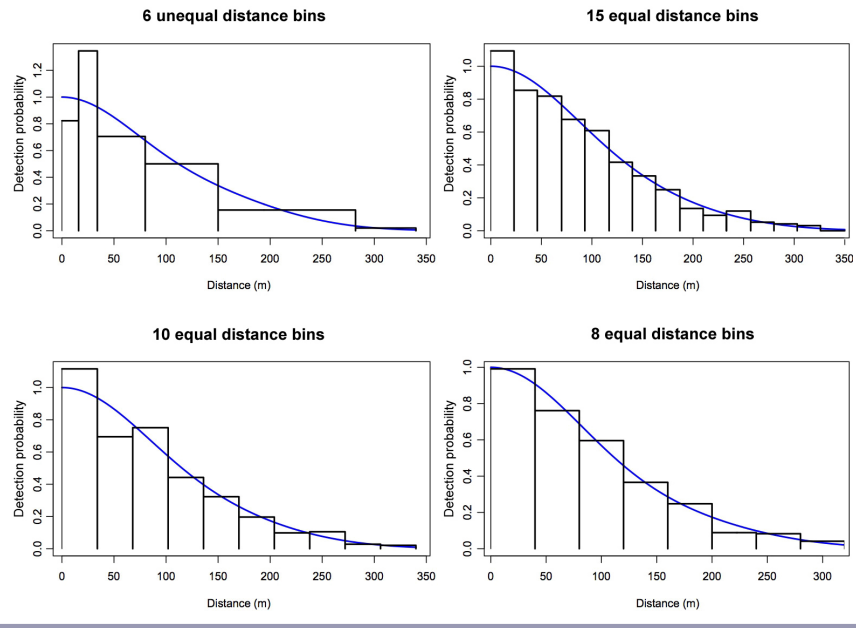
Table 2. Point estimates for the density $(D)$ and abundance $(N)$ of phalaropes by survey date based on detection models fitted to each of four dataset partitions (region:yr). Density refers to number of phalaropes per square kilometer. Percent coefficient of variation in $D$ and $N$ as estimated by the four models was: 13.58, 23.70, 18.70, 16.45 for Brier 2009, 2010, GM 2009, 2010, respectively. Standard error (SE) for density and confidence intervals $(95 \% \mathrm{CI})$ for abundance estimates are shown. Inference about the abundance of phalaropes by survey date was restricted to the covered region only: $175 \mathrm{~km}^{2}$ in Brier, $145 \mathrm{~km}^{2}$ in Grand Manan.

\begin{tabular}{|c|c|c|c|c|c|c|c|c|c|}
\hline \multicolumn{5}{|c|}{ Brier 2009} & \multicolumn{5}{|c|}{ Brier 2010} \\
\hline$\underline{\text { Date }}$ & $D$ & SE & $N$ & $95 \% \mathrm{CI}$ & Date & $D$ & SE & $N$ & $95 \% \mathrm{CI}$ \\
\hline July 31 & 38.9 & 5.29 & 6824 & $5234-8897$ & July 26 & 102.2 & 24.23 & 17,896 & $11,289-28,370$ \\
\hline Aug 1 & 199.3 & 27.05 & 34,877 & $26,749-45,474$ & July 31 & 249.9 & 59.23 & 43,745 & $27,594-69,348$ \\
\hline Aug 6 & 168.9 & 22.93 & 29,570 & $22,679-38,554$ & Aug 11 & 426.0 & 100.96 & 74,565 & $47,036-118,210$ \\
\hline Aug 8 & 402.9 & 54.70 & 70,512 & $54,080-91,936$ & Aug 13 & 142.0 & 33.65 & 24,855 & $15,679-39,402$ \\
\hline Aug 9 & 164.6 & 22.35 & 28,811 & $22,097-37,565$ & Aug 18 & 210.2 & 49.80 & 36,786 & $23,204-58,315$ \\
\hline Aug 12 & 142.9 & 19.41 & 25,020 & $19,190-32,623$ & Aug 25 & 409.0 & 96.92 & 71,583 & $45,155-113,480$ \\
\hline Aug 20 & 173.3 & 23.52 & 30,328 & $23,260-39,543$ & Aug 30 & 267.0 & 63.27 & 46,728 & $29,476-74,076$ \\
\hline Aug 27 & 177.6 & 24.11 & 31,086 & $22,679-38,554$ & Sept 9 & 119.3 & 28.27 & 20,878 & $13,170-33,098$ \\
\hline Sept 1 & 168.9 & 22.93 & 29,570 & $22,679-38,554$ & Sept 13 & 335.1 & 79.42 & 58,658 & $37,002-92,990$ \\
\hline Sept 2 & 238.2 & 32.34 & 41,701 & $31,983-54,371$ & Sept 23 & 539.7 & 127.89 & 94,449 & $59,579-149,730$ \\
\hline Sept 9 & 60.6 & 8.23 & 10,615 & $8141-13,840$ & Sept 27 & 176.1 & 41.73 & 30,820 & $19,442-48,859$ \\
\hline Sept 10 & 56.3 & 7.64 & 9857 & $7560-12,851$ & Oct 3 & 147.7 & 35.00 & 25,849 & $16,306-40,978$ \\
\hline Sept 14 & 38.9 & 5.29 & 6824 & $5234-8897$ & Oct 12 & 181.8 & 43.07 & 31,815 & $20,069-50,435$ \\
\hline
\end{tabular}

Grand Manan 2009

\begin{tabular}{|c|c|c|c|c|c|c|c|c|c|}
\hline \multicolumn{5}{|c|}{ Grand Manan 2009} & \multicolumn{5}{|c|}{ Grand Manan 2010} \\
\hline Date & $D$ & $\mathrm{SE}$ & $N$ & $95 \% \mathrm{CI}$ & Date & $D$ & $\mathrm{SE}$ & $N$ & $95 \% \mathrm{CI}$ \\
\hline Aug 1 & 194.5 & 36.39 & 28,216 & $19,595-40,628$ & July 26 & 90.6 & 14.90 & 13,141 & $9525-18,130$ \\
\hline Aug 8 & 125.3 & 23.43 & 18,173 & $12,621-26,167$ & July 31 & 527.7 & 86.82 & 76,525 & $55,466-105,580$ \\
\hline Aug 12 & 118.7 & 22.20 & 17,216 & $11,956-24,790$ & Aug 11 & 202.5 & 33.32 & 29,373 & $21,290-40,526$ \\
\hline Aug 20 & 6.5 & 1.23 & 956 & $664-1377$ & Aug 13 & 373.1 & 61.38 & 54,109 & $39,219-74,653$ \\
\hline Aug 27 & 32.9 & 6.16 & 4,782 & $3321-6886$ & Aug 18 & 234.5 & 38.58 & 34,011 & $24,652-46,924$ \\
\hline Sept 1 & 75.8 & 14.18 & 10,999 & $7639-15,838$ & Aug 25 & 138.6 & 22.80 & 20,098 & $14,567-27,728$ \\
\hline Sept 2 & 46.1 & 8.63 & 6695 & $4650-9641$ & Aug 30 & 559.7 & 92.08 & 81,163 & $58,828-111,980$ \\
\hline Sept 10 & 19.7 & 3.70 & 2,869 & $1993-4132$ & Sept 9 & 79.9 & 13.15 & 11,595 & $8404-15,997$ \\
\hline \multirow[t]{4}{*}{ Sept 14} & 3.2 & 0.61 & 478 & $332-689$ & Sept 13 & 346.5 & 57.00 & 50,244 & $36,417-69,320$ \\
\hline & & & & & Sept 23 & 298.5 & 49.11 & 43,287 & $31,375-59,722$ \\
\hline & & & & & Sept 27 & 282.5 & 46.47 & 40,968 & $29,694-56,523$ \\
\hline & & & & & Oct 3 & 154.6 & 25.43 & 22,417 & $16,248-30,927$ \\
\hline
\end{tabular}

Distance sampling methods may be used to infer abundance to a wider area in which line transects are evenly distributed or, more conservatively, to an area demarcated by the line transects themselves. We observed high percent coefficient of variation in the daily abundance estimates generated by detection models. Therefore, we opted to restrict inference about the abundance of phalaropes to the strip of sea repeatedly overflown by aerial surveys, i.e., the covered region only. Our line transects were laid out in two survey regions with an area of $633 \mathrm{~km}^{2}$ (Brier) and 531 $\mathrm{km}^{2}$ (Grand Manan). Within each area, we delimited a search strip by the length of transects $(250 \mathrm{~km}$ in Brier, $207 \mathrm{~km}$ in Grand Manan) and width of transects ( $700 \mathrm{~m}$ given the available field of view). Accordingly, area of the covered region only was $175 \mathrm{~km}^{2}$ in Brier and $145 \mathrm{~km}^{2}$ in Grand Manan.

Component sources of uncertainty in our density estimates were detection probability and cluster size. Cluster size was responsible for the largest percent of variance: 85.7, 98.3 in Brier 2009, 2010 and 84.9, 96.9 in Grand Manan 2009, 2010. In correcting for size bias, expected flock size was: $E(s) \pm S E=138 \pm 17.3,163 \pm 38.3$ in Brier 2009, 2010 and $67 \pm 11.5,104 \pm 16.9$ in Grand Manan 2009,2010 . Estimated density of phalaropes $/ \mathrm{km}^{2}$ in 2009 ranged from low (39 in Brier, 3 in Grand Manan) to high (403 in Brier,
195 in Grand Manan) with peak densities occurring in early August. In 2010, density ranged from low (102 in Brier, 80 in Grand Manan) to high (540 in Brier, 560 in Grand Manan), with peaks occurring in late July, late August and late September.

Prior to finding the cumulative number of phalaropes for all values of date and abundance, "bird days," the sum of $N$ values by date in Brier and Grand Manan was taken to derive a combined abundance (Total $N$ ) across the study area for each survey date in 2009 and 2010. It must be emphasized that in 2009, three survey attempts were curtailed because of fog over Grand Manan; abundance estimates were returned for Brier only on 31 July, 6 August, and 9 August. As snapshots of stopover abundance at discrete time steps, the combined abundance values used to calculate size of the total stopover population, adjusting for length of stay, are given in Table 3 .

Among the 27 phalaropes fitted with a radio tag, species ratio differed widely across years with numbers of Red-necked to Red $7: 0,5: 3,0: 12$ in $2008,2009,2010$. We fitted a probability density function to the pooled observation times from all individuals and all years to estimate length of stay. The model with lowest $\mathrm{AIC}_{c}$ was based on a uniform key with cosine adjustment term. Estimated length of stay in days $(L O S \pm \mathrm{SE})$ was $15.2 \pm 1.9$ with $95 \%$ confidence limits at $11.8-19.7$. 
Table 3. Combined abundance (Total $N$ ) of phalaropes in the study area by survey date, based on the sum of $N$ by survey date in both Brier and Grand Manan. Results of numerical integration to find bird days (BD) and quantify stopover population size (pop) adjusting for length of stay are given. Estimated length of stay $(L O S)$ was derived by fitting a probability density function to the observation times of radiomarked birds $(n=27)$ captured in 2008, 2009, and 2010.

\begin{tabular}{|c|c|c|c|}
\hline \multicolumn{2}{|c|}{2009} & \multicolumn{2}{|c|}{2010} \\
\hline Date & Total $N$ & Date & Total $N$ \\
\hline$\overline{\mathrm{Jul}} 31^{\dagger}$ & 6824 & July 26 & 31,037 \\
\hline Aug 1 & 63,093 & July 31 & 120,270 \\
\hline Aug $6^{\dagger}$ & 29,570 & Aug 11 & 103,938 \\
\hline Aug 8 & 88,685 & Aug 13 & 78,964 \\
\hline Aug $9^{\dagger}$ & 28,811 & Aug 18 & 70,797 \\
\hline Aug 12 & 42,236 & Aug 25 & 91,681 \\
\hline Aug 20 & 31,284 & Aug 30 & 127,891 \\
\hline Aug 27 & 35,868 & Sept 9 & 32,473 \\
\hline Sept 1 & 40,569 & Sept 13 & 108,902 \\
\hline Sept 2 & 48,396 & Sept 23 & 137,736 \\
\hline Sept 9 & 10,615 & Sept 27 & 71,788 \\
\hline Sept 10 & 12,726 & Oct 3 & 48,266 \\
\hline Sept 14 & 7302 & Oct 12 & 31,815 \\
\hline \multicolumn{2}{|c|}{ Survey period $=45$ days } & \multicolumn{2}{|c|}{ Survey period $=49$ days } \\
\hline $\mathrm{BD}$ & $1,573,142$ & $\mathrm{BD}$ & $4,370,889$ \\
\hline$L O S$ & 15.2 & $\operatorname{LOS}$ & 15.2 \\
\hline \multirow[t]{5}{*}{ pop } & 103,496 & pop & 287,558 \\
\hline & & \multicolumn{2}{|c|}{ Survey period $=78$ days } \\
\hline & & BD & $6,743,654$ \\
\hline & & $L O S$ & 15.2 \\
\hline & & pop & 443,661 \\
\hline
\end{tabular}

Estimated size of the total stopover population of phalaropes in 2009 was 103 thousand. The time frame for surveys in 2009 was 45 days. By contrast, in 2010 the time frame was 78 days because flocks remained in the study area and we continued to fly surveys until mid-October. Based on consensus as to the timing of phalarope migration in the region (Orr et al. 1982, Rubega et al. 2000, Tracy et al. 2002), it was unusual to observe large flocks in the region beyond September. However, our aerial survey coverage suggests that the stopover site tenure of postbreeding phalaropes in the Bay Fundy may be subject to more variation than previously thought. For comparison, we report stopover population size in 2010 for a 49-day period ending on September 13th (287 thousand), and for the full 78-day period (443 thousand), assuming a constant length of stay of 15 days.

Species ratios were gathered for a sample of flocks encountered opportunistically near the Brier ledges in 2010. Between 21 July and 31 August, we conducted 12 boat trips on calm days with flat seas (Beaufort 0-1), during which we were able to approach and photograph 43 flocks resting or feeding on the water. Taken together, the proportion of phalaropes positively identified as $P$. lobatus was $53 \%$.

\section{DISCUSSION}

In this study, the choice of survey platform introduced several factors that likely influenced our stopover abundance estimates.
An aircraft was critical to achieving our goal of obtaining comprehensive abundance data on small, highly mobile migratory birds at sea. Brown and Gaskin (1988) characterized the ecology phalaropes in the outer Bay of Fundy as closely tied to the Brier ledges, which act as "tidal pumps" and provide a nexus for phalarope flocks in the region. Quantitative evidence provided by Thorne and Read (2013) substantiates their hypothesis. However, our aerial perspective revealed that large flocks occur in "offledge" areas as well, and that while the ledges provide a focal point for their collective movements, flocks shift widely about them $\left(100 \mathrm{~s} \mathrm{~km}^{2}\right)$ in the span of hours. The dynamic nature of this system imparts a complexity to phalarope occurrence patterns and has a large bearing on the choice of platform to assess them comprehensively.

Aircraft provide certain advantages over boats for surveys at sea, notably an ability to cover large areas $\left(100 \mathrm{~s}\right.$ of $\left.\mathrm{km}^{2}\right)$ in a short time window (hours), but trade-offs to the increased encounter rate include reduced observer acuity overall (Caughley 1974, Pollock and Kendall 1987, Marsh and Sinclair 1989, Pollock et al. 2006). As a remedy, boat-based surveys allow for detailed observation at close range, but boats must operate with some dependence on "hotspots" as a means of encountering mobile assemblages of birds at sea. As such, they are confined to small search areas $\left(10-15 \mathrm{~km}^{2}\right)$, a feature that limits the utility of boats for surveying phalaropes in the outer Bay of Fundy. In sum, the primary drawback of aircraft for surveys is incomplete detection whereas for boats the problem is one of incomplete coverage. Given the high mobility of phalarope flocks, we concluded that aerial surveys allow for a more synoptic picture.

Our results highlight several issues to be considered when designing studies of small marine birds using aerial line transect methods. The speed of an aircraft allows greater coverage, but entails an increased chance of missing target objects in the search strip. As near-line objects pass through the field of view up to $4 \mathrm{x}$ faster than objects near-horizon (Fleming and Tracey 2008), higher altitude allows more time for visual detection. On the other hand, if higher altitude imposes a nontrivial distance between observer and objects below, it reverts to the same drawback brought about by lower altitude, which reduces distance to target objects, but affords less time to process sightings from the air (Buckland et al. 2001).

These are classic pitfalls known to affect aerial surveys and, potentially, to introduce visibility bias into estimation procedures used to obtain abundance estimates from them (Laake et al. $2008 a$ ). In our case, a key consideration for the utility of distance sampling is a requirement for uniform distances (Fewster et al. 2008). Our empirical distance data showed that features of the aerial sighting situation led to visibility bias that may have translated into a violation of the uniform requirement, interfering with our estimators of detection probability. We discuss two scenarios that likely gave rise to a spiked pattern in our distance data: (1) impaired downward visibility induced by the flat-sided windows, such that detections in the first sighting bin were harder to obtain than in the second (Laake et al. 2008b). In a plane with flat-sided windows, it is generally easier for an observer to search slightly away from the first sighting bin and to favor the second; (2) influence of animal movement and in particular, evasive movement from the flightpath. If flocks flushed away from the first sighting bin and into the second before being recorded, this 
would also give rise to the nonuniform pattern of detection reported here. In support of scenario 2, phalaropes were observed to flush from the flightpath during surveys. Paradoxically, this response served as a valuable cue for visual detection (cf. Southwell et al. 2008).

In the absence of mark-recapture methods, it is difficult to gauge whether either scenario was severe enough to cause genuine nonuniformity in our data (Borchers et al. 2006). We speculate that a mixture was at play and a potential outcome is that our estimators for detection probability are positively biased. When estimators for detection probability are too high, compensation for abundance will be too low, and the degree to which abundance is underestimated is proportional to the true detection probability (Laake et al. 2008a). Nevertheless, our results clearly show there has been a significant decline in numbers of $P$. lobatus that pass through the Bay of Fundy. Based on previous counts, total stopover passage at Head Harbour from July-September included some 2 million migrants of $P$. lobatus, with daily densities of 5000-20,000 birds $/ \mathrm{km}^{2}$ (Mercier and Gaskin 1985). By contrast, highest recorded density comprising both species of phalarope as evaluated in the present study was 560 birds $/ \mathrm{km}^{2}$. Even without applying a species ratio to the abundance estimates reported here, this amounts to a steep reduction in numbers of $P$. lobatus observed at Head Harbour prior to their abrupt disappearance in the 1980s.

The upheaval of phalaropes from Head Harbour in the 1980s remains a matter of speculation in terms of demography. Although the event has been characterized as a disproportionate local decline, consensus from literature is that its impact on the species in North America is unknown (Duncan 1996, Rubega et al. 2000, Brown et al. 2010). The level of uncertainty is reflected in a population size estimate for P. lobatus in North America: in their reassessment of population size and trend of 52 species and 75 taxa of shorebirds occurring in North America, Andres et al. (2012) report the figure for P. lobatus at 2.5 million. They note that the estimate is highly problematic because it includes historic counts from Head Harbour prior to the disappearance and has not been revised from compilations on shorebird numbers in North America, first published in 2001 (Morrison et al. 2001) and updated in 2006 (Morrison et al. 2006).

Explanatory frameworks for the Head Harbour disappearance can be broken into two categories: (1) population crash; (2) shift in migratory stopover pathway. In support of the first hypothesis, Nisbet and Veit (2015) have proposed the largest part of the decline at Head Harbour was well underway by 1984 and thus can be linked to El Nino-Southern Oscillation (ENSO) events affecting the wintering area. The authors noted that severe ENSO conditions depleted marine ecosystems in the eastern tropical Pacific in 1982/1983. In the Western Hemisphere, the only known major wintering area for $P$. lobatus is the Humboldt Current off Ecuador, Peru, and northern Chile (Murphy 1936, Rubega et al. 2000, but see Haney 1985). Although migrants of $P$. fulicarius winter here too, those that pass through Fundy in autumn are thought to winter in the Canary and Benguela Currents off West Africa (Cramp and Simmons 1982).

This may in part explain why there was not a crash in the outer Bay of Fundy where, based on summary assessments from Brier Island (Brown and Gaskin 1988), smaller assemblages of phalaropes (10s of thousands) occurred through the 1970s and 1980 s and no strict segregation of species, such as that distinguishing Head Harbour, has been reported. However, any perception that the outer Fundy stopover population was insulated from the decline at Head Harbour bears scrutiny: anecdotal observations suggest that $P$. fulicarius often outnumbered P. lobatus, by as much as 95:5, at the Brier ledge areas prior to the Head Harbour disappearance, but the species ratio changed measurably, at times approaching 1:20, in its aftermath in 1990 (Brown 1991). As evaluated for the present study, species ratio at the Brier ledges was found to be closer to 50:50 overall in 2010 .

Others have proposed a local disturbance affecting prey availability as being responsible for the Head Harbour disappearance (Brown et al. 2010), leading to a shift in migratory pathway and supplying migrants elsewhere. In 1990, there was some indication that zooplankton density was low at Head Harbour in August. Against this, more rigorous plankton tows returned extremely high density values in October (Duncan 1996). The second hypothesis would be better substantiated if population trends observed on Arctic breeding grounds had remained stable overall, but this is not the case for either species of phalarope: survey counts are sparse, but declines were reported at Arctic breeding sites (La Pérouse Bay, Manitoba; Prudhoe Bay, Alaska) in the wake of ENSO 1982/1983 (see Nisbet and Veit 2015). Although the authors acknowledge these declines to be far less pronounced and sustained than the Head Harbour crash, such findings undermine a shift hypothesis because breeding populations of $P$. lobatus should have remained stable if not increasing had 1-2 million birds simply altered their migratory stopover pathway.

None of the above frameworks has sufficient scope without quantitative information on phalarope populations on the breeding grounds, wintering areas, and critical stopovers between. This study provides the first attempt to obtain comprehensive estimates of phalarope stopover abundance in the Atlantic, while adjusting for estimated length of stay. Our work provides baseline information essential for evaluating the importance of the Bay of Fundy to phalaropes in general. Recent geolocator evidence gathered by Smith et al. 2014 offers an intriguing example of a trans-Atlantic Ocean migratory route in which the Bay of Fundy provided a stopover to a bird breeding in Shetland, UK (Smith et al. 2014). We urge the development of surveys to track phalaropes at sea, where they concentrate reliably and spend the majority of their time.

Responses to this article can be read online at: http://www.ace-eco.org/issues/responses.php/926

\section{Acknowledgments:}

Sincere thanks to the team at the Grand Manan Whale and Searbird Research Station, especially Andrew Westgate, Sarah Wong, and Zach Swaim for their skill and persistence in the field. Aerial surveys were made possible by Atlantic Charters of Grand Manan and we thank Klaus and Peter Sonnenberg for their expertise as pilots. Special thanks to Christopher Julian, for design of tools used in the 
field, and Reid Gillis for long hours of boat maneuvering under challenging conditions. Brier Island Whale and Seabird Cruises generously provided boat-based support and we are grateful to Harold Graham for housing as well. Funding was provided by U.S. Fish \& Wildlife Service Region 5, Manomet Center for Conservation Sciences, and Environment Canada. Many insightful discussions contributed to the design of this study; in particular, we thank Dan McCauley, John Chardine, Lesley Thorne, and Charles Duncan. We greatly thank Carina Gjerdrum, Rob Ronconi, and Julie Paquet for helpful reviews of this manuscript.

\section{LITERATURE CITED}

Alldredge, J. R., and C. E. Gates. 1985. Line transect estimators for left-truncated distributions. Biometrics 41:273-280. http://dx. doi.org/10.2307/2530663

Andres, B. A., P. Smith, R. I. G. Morrison, C. Gratto-Trevor, S. Brown, and C. Friis. 2012. Population estimates of North American Shorebirds, 2012. Wader Study Group Bulletin 119 (3):178-192.

Aretxabaleta, A. L., D. J. McGillicuddy Jr., K.W. Smith, and D. R. Lynch. 2008. Model simulations of the Bay of Fundy gyre: 1. climatological results. Journal of Geophysical Research-Oceans 113(C10):C10027. http://dx.doi.org/10.1029/2007JC004480

Bengston, J., A. S. Blix, I. L. Boyd, M. F. Cameron, M. B. Hanson, and J. L. Laake. 1996. Antarctic pack-ice seal research, February and March 1995. Antarctic Journal 30(5):191-193.

Borchers, D. L., J. Laake, C. Southwell, and C. G. M. Paxton. 2006. Accommodating unmodeled heterogeneity in doubleobserver distance sampling surveys. Biometrics 62:372-378. http:// dx.doi.org/10.1111/j.1541-0420.2005.00493.x

Bost, C. A., C. Cotté, F. Bailleul, Y. Cherel, J. B. Charrassin, C. Guinet, D. G. Ainley, and H. Weimerskirch. 2009. The importance of oceanographic fronts to marine birds and mammals of the southern oceans. Journal of Marine Systems 78(3):363-76. http:// dx.doi.org/10.1016/j.jmarsys.2008.11.022

Briggs, K. T., F. Dettman, D. B. Lewis, and W. B. Tyler. 1984. Phalarope feeding in relation to autumn upwelling off California. Pages 51-62 in D. N. Nettleship, G. A. Sanger, and P. F. Springer, editors. Marine Birds: their feeding ecology and commercial fisheries relationships. Special publication compiled by Canadian Wildlife Service for Pacific Seabird Group, Ottawa, Ontario, Canada.

Brown, R. G. B. 1991. The great Fundy phalarope mystery. Nova Scotia Birds 33:58-59.

Brown, R. G. B., and D. E. Gaskin. 1988. The pelagic ecology of the Grey and Red-necked Phalaropes Phalaropus-fulicarius and P. lobatus in the Bay of Fundy, eastern Canada. Ibis 130 (2):234-250. http://dx.doi.org/10.1111/j.1474-919x.1988.tb00974. $\mathrm{x}$

Brown, S., C. Duncan, J. Chardine, and M. Howe. 2010. Version 1.1. Red-necked Phalarope research, monitoring and conservation plan for the northeastern U.S. and Maritimes Canada. Manomet Center for Conservation Sciences, Manomet, Massachusetts USA.
Brown, S., C. Hickey, B. Harrington, and R. Gill, editors. 2001. United States shorebird conservation plan. Second edition. Manomet Center for Conservation Sciences, Manomet, Massachusetts USA.

Buckland, S. T., D. R. Anderson, K. P. Burnham, J. L. Laake, D. L. Borchers, and L. Thomas. 2001. Introduction to distance sampling: estimating abundance of biological populations. Oxford University Press, Oxford, UK.

Buckland, S. T., D. R. Anderson, K. P. Burnham, J. L. Laake, D. L. Borchers, and L. Thomas. 2004. Advanced distance sampling. Oxford University Press, Oxford, UK.

Caughley, G. 1974. Bias in aerial survey. Journal of Wildlife Management 38:921-933. http://dx.doi.org/10.2307/3800067

Cramp, S., and K. E. L. Simmons, editors. 1982. The birds of the western Palearctic. Vol. III: waders to gulls. Oxford University Press, Oxford, UK.

DiGiacomo, P. M., W. M. Hamner, P. P. Hamner, and R. M. A. Caldeira. 2002. Phalaropes feeding at a coastal front in Santa Monica Bay, California. Journal of Marine Systems 37 (1-3):199-212. http://dx.doi.org/10.1016/s0924-7963(02)00202-6

Donaldson, G. M., C. Hyslop, R. I. G. Morrison, H. L. Dickson, and I. Davidson. 2000. Canadian shorebird conservation plan. Canadian Wildlife Service Special Publications. Canadian Wildlife Service, Ottawa, Ontario, Canada.

Duncan, C. D. 1996. The migration of Red-necked Phalaropes: ecological mysteries and conservation concerns. Birding 28:482-488.

Farmer, A., and F. Durbian. 2006. Estimating shorebird numbers at migration stopover sites. Condor 108(4):792-807. http://dx.doi. org/10.1650/0010-5422(2006)108[792:esnams]2.0.co;2

Fewster, R. M., S. T. Buckland, K. P. Burnham, D. L. Borchers, P. E. Jupp, J. L. Laake, and L. Thomas. 2009. Estimating the encounter rate variance in distance sampling. Biometrics 65 (1):225-236. http://dx.doi.org/10.1111/j.1541-0420.2008.01018.x

Fewster, R. M., C. Southwell, D. L. Borchers, S. T. Buckland, and A. R. Pople. 2008. The influence of animal mobility on the assumption of uniform distances in aerial line-transect surveys. Wildlife Research 35(4):275-288. http://dx.doi.org/10.1071/ wr07077

Finch, D. W., W. C. Russell, and E. V. Thompson. 1978. Pelagic birds in the Gulf of Maine. American Birds 32:281-294.

Fleming, P. J. S., and J. P. Tracey. 2008. Some human, aircraft and animal factors affecting aerial surveys: how to enumerate animals from the air. Wildlife Research 35(4):258-267. http://dx.doi. org/10.1071/wr07081

Franks, P. J. S. 1992. Sink or swim: accumulation of biomass at fronts. Marine Ecology Progress Series 82:1-12. http://dx.doi. org/10.3354/meps082001

Genin, A. 2004. Bio-physical coupling in the formation of zooplankton and fish aggregations over abrupt topographies. Journal of Marine Systems 50(1-2):3-20. http://dx.doi. org/10.1016/j.jmarsys.2003.10.008 
Haney, J. C. 1985. Wintering phalaropes off the southeastern United States: application of remote sensing imagery to seabird habitat and analysis of oceanic fronts. Journal of Field Ornithology 56:321-333.

Herr, H., M. Scheidat, K. Lehnert, and U. Siebert. 2009. Seals at sea: modelling seal distribution in the German bight based on aerial survey data. Marine Biology 156(5):811-820. http://dx.doi. org/10.1007/s00227-008-1105-X

Hunt, G. L., Jr., R. W. Russell, K. O. Coyle, and T. Weingartner. 1998. Comparative foraging ecology of planktivorous auklets in relation to ocean physics and prey availability. Marine Ecology Progress Series 167:241-259. http://dx.doi.org/10.3354/meps167241

Iverson, G. C., S. E. Warnock, R. W. Butler, M. A. Bishop, and N. Warnock. 1996. Spring migration of Western Sandpipers along the Pacific Coast of North America: a telemetry study. Condor 98:10-21. http://dx.doi.org/10.2307/1369502

Laake, J., M. J. Dawson, and J. Hone. 2008a. Visibility bias in aerial survey: mark-recapture, line-transect or both? Wildlife Research 35(4):299-309. http://dx.doi.org/10.1071/WR07034

Laake, J., R. J. Guenzel, J. L. Bengtson, P. Boveng, M. Cameron, and M. B. Hanson. 2008b. Coping with variation in aerial survey protocol for line-transect sampling. Wildlife Research 35 (4):289-298. http://dx.doi.org/10.1071/WR07065

Lehnen, S. E., and D. G. Krementz. 2005. Turnover rates of fallmigrating pectoral sandpipers in the lower Mississippi alluvial valley. Journal of Wildlife Management 69(2):671-680. http://dx. doi.org/10.2193/0022-541x(2005)069[0671:trofps]2.0.co;2

Marsh, H., and D. F. Sinclair. 1989. Correcting for visibility bias in strip transect aerial surveys of aquatic fauna. Journal of Wildlife Management 53:1017-1024. http://dx.doi.org/10.2307/3809604

Mercier, F. M., and D. E. Gaskin. 1985. Feeding ecology of migrating Red-necked Phalaropes (Phalaropus lobatus) in the Quoddy region, New Brunswick, Canada. Canadian Journal of Zoology 63(5):1062-1067. http://dx.doi.org/10.1139/z85-159

Morrison, R. I. G., R. E. Gill, B. A. Harrington, S. K. Skagen, G. W. Page, C. L. Gratto-Trevor, and S. M. Haig. 2001. Estimates of shorebird populations in North America. Canadian Wildlife Service Occasional Paper no. 104. Canadian Wildlife Service, Ottawa, Ontario, Canada.

Morrison, R. I. G., B. J. McCaffery, R. E. Gill, S. K. Skagen, S. L. Jones, G. W. Page, C. L. Gratto-Trevor, and B. A. Andres. 2006. Population estimates of North American shorebirds, 2006. Wader Study Group Bulletin 111:67-85.

Murphy, R. C. 1936. Oceanic birds of South America. Vol. 2, American Museum of Natural History, New York, New York, USA.

Nisbet, I. C., and R. R. Veit. 2015. An explanation for the population crash of Red-necked Phalaropes (Phalaropus lobatus) staging in the Bay of Fundy in the 1980s. Marine Ornithology 43:119-121.

Obst, B. S., and G. L. Hunt Jr. 1990. Marine birds feed at gray whale mud plumes in the Bering Sea. Auk 107(4):678-688. http:// dx.doi.org/10.2307/4087998
Orr, C. D., R. M. P. Ward, N. A. Williams, and R. G. B. Brown. 1982. Migration patterns of Red and Northern Phalaropes in Southwest Davis Strait and in the Northern Labrador Sea. Wilson Bulletin 94(3):303-312.

Otis, D. L., L. L. Mcdonald, and M. A. Evans. 1993. Parameterestimation in encounter sampling surveys. Journal of Wildlife Management 57(3):543-548. http://dx.doi.org/10.2307/3809280

Pollock, K. H., and W. L. Kendall. 1987. Visibility bias in aerial surveys: a review of estimation procedures. Journal of Wildlife Management 51:502-510. http://dx.doi.org/10.2307/3801040

Pollock, K. H., H. D. Marsh, I. R. Lawler, and M. W. Alldredge. 2006. Estimating animal abundance in heterogeneous environments: an application to aerial surveys for dugongs. Journal of Wildlife Management 70(1):255-262. http://dx.doi. org/10.2193/0022-541x(2006)70[255:eaaihe]2.0.co;2

Quang, P. X., and R. B. Lanctot. 1991. A line-transect model for aerial surveys. Biometrics 47:1089-1102. http://dx.doi. org/10.2307/2532661

Ronconi, R. A., Z. T. Swaim, H. A. Lane, R. W. Hunnewell, A. J. Westgate, and H. N. Koopman. 2010. Modified hoop-net techniques for capturing birds at sea and comparison with other capture methods. Marine Ornithology 38:23-29.

Rubega, M. A., D. Schamel, and D. M. Tracy. 2000. Red-necked Phalarope (Phalaropus lobatus). In A. Poole, editor. The birds of North America online. Cornell Lab of Ornithology, Ithaca, New York, USA. http://dx.doi.org/10.2173/bna.538

Smith, M., M. Bolton, D. J. Okill, R. W. Summers, P. Ellis, F. Liechti, and J. D. Wilson. 2014. Geolocator tagging reveals Pacific migration of Red-necked Phalarope Phalaropus lobatus breeding in Scotland. Ibis 156:870-873. http://dx.doi.org/10.1111/ ibi. 12196

Southwell, C., C. G. M. Paxton, and D. L. Borchers. 2008. Detectability of penguins in aerial surveys over the pack-ice off Antarctica. Wildlife Research 35(4):349-357. http://dx.doi. org/10.1071/wr07093

Thomas, L., S. T. Buckland, E. A. Rexstad, J. L. Laake, S. Strindberg, S. L. Hedley, J. R. B. Bishop, T. A. Marques, and K. P. Burnham. 2010. Distance software: design and analysis of distance sampling surveys for estimating population size. Journal of Applied Ecology 47:5-14. http://dx.doi.org/10.1111/

j.1365-2664.2009.01737.x

Thomas, L., R. Williams, and D. Sandilands. 2007. Designing line transect surveys for complex survey regions. Journal of Cetacean Research Management 9(1):1-13.

Thorne, L. H., and A. J. Read. 2013. Fine-scale biophysical interactions drive prey availability at a migratory stopover site for Phalaropus spp. in the Bay of Fundy, Canada. Marine Ecology Progress Series 487:261-273. http://dx.doi.org/10.3354/meps10384

Tracy, D. M., D. Schamel, and J. Dale. 2002. Red Phalarope (Phalaropus fulicarius). In A Poole, editor. The birds of North America online. Cornell Lab of Ornithology, Ithaca, New York, USA. http://dx.doi.org/10.2173/bna.698

Vickery, P. D. 1978. The fall migration: northeastern Maritime region. American Birds 32:174-180. 
Warnock, N., C. Elphick, and M. A. Rubega. 2002. Shorebirds in the marine environment. Pages 581-615 in E. A. Shreiber and J. Burger, editors. Biology of marine birds. CRC, Boca Raton, Florida, USA.

Wolanski, E., and W. M. Hamner. 1988. Topographically controlled fronts in the ocean and their biological influence. Science 241(4862):177-181. http://dx.doi.org/10.1126/science.241.4862.177

Yen, P. P. W., W. J. Sydeman, and K. D. Hyrenbach. 2004. Marine bird and cetacean associations with bathymetric habitats and shallow-water topographies: implications for trophic transfer and conservation. Journal of Marine Systems 50(1-2):79-99. http://dx. doi.org/10.1016/j.jmarsys.2003.09.015 